\title{
Online Investigation of Optical Properties and Craze Propagation of Drawn Polypropylene Fiber by Using Interferometric Image Analysis
}

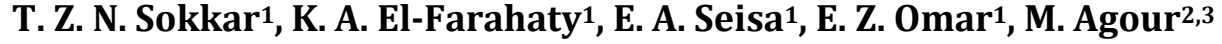 \\ ${ }^{1}$ Physics Department, Faculty of Science, Mansura University, Mansura, Egypt \\ ${ }^{2}$ Physics Department, Faculty of Science, Aswan University, Aswan, Egypt \\ ${ }^{3}$ Physics Department, FB1: Physics and Electrical Engineering, Bremen University, Bremen, Germany \\ Email:emam8810@yahoo.com
}

Received 24 May 2014; revised 21 June 2014; accepted 15 July 2014

Copyright $(\subset 2014$ by authors and Scientific Research Publishing Inc.

This work is licensed under the Creative Commons Attribution International License (CC BY). http://creativecommons.org/licenses/by/4.0/

(c) (i) Open Access

\begin{abstract}
Pluta polarizing interference microscope was used to follow the crazing that occur on the surface of stretched polypropylene fibres at different drawing conditions. The samples were stretched until crazing initiated, and then craze propagation was monitored as a function of drawing speed and test temperature. The effect of craze dimension on their propagation velocity was taken into account. Three-dimensional birefringence profile for crazed polypropylene fibre has been demonstrated to investigate the birefringence of crazed fibre at different test times for fixed drawing speed value. Also the mean birefringence values of crazed polypropylene fibres were calculated and the results showed that, these values increased with the areal craze density. Video images were used to calculate the craze velocity. Optical micrographs and microinterferograms were presented for demonstrations.
\end{abstract}

\section{Keywords}

Areal Craze Density, Craze Propagation Velocity, Polypropylene Fibre, Pluta Polarizing Interference Microscope, Microscopic Image Analysis System (MIAS)

\section{Introduction}

The phenomena of crazing can be considered as an important deformation and fracture mechanism. It represents

How to cite this paper: Sokkar, T.Z.N., El-Farahaty, K.A., Seisa, E.A., Omar, E.Z. and Agour, M. (2014) Online Investigation of Optical Properties and Craze Propagation of Drawn Polypropylene Fiber by Using Interferometric Image Analysis. Optics and Photonics Journal, 4, 165-181. http://dx.doi.org/10.4236/opj.2014.47017 
the first stage of the deformation and fracture process in polymer. Craze morphology was first described by Kembour in 1973 [1]. The ideal structure of the craze includes microviods which are developed on the perpendicular plane to the main tensile direction. These microvoids are stabilized temporally by microfibrils of material which act as bridges in a microcrack, allowing the load to be transmitted. The stabilization by fibril will fail and a craze-crack transition occurs followed by actual failure. Figure 1 shows a schematic diagram for the ideal structure of the craze [2]-[4].

Crazing process contains three main stages [3]-[8]: craze initiation, craze propagation and craze breakdown. Craze initiation starts by extension of the chain coils and pulling them from the bulk material giving rise to microfibrils bridging. The large contrast between inter-chain and strong intra-chain is the main reason for the occurrence of this phenomenon. Once the craze is formed, it will propagate by 1) lengthening (craze tip advanced) which is known as a meniscus instability propagation and 2) crazes widen (drawing) which represents a new material produced into the fibrils from the active zone, (which is a thin region of the strain softened polymer at the craze/ bulk interface in craze breakdown). Finally the microfibrils rupture converts the craze into a crack by either chain scission or chain disentanglement, depending on the applied temperature and the chain length. The crazes are treated as cracks bridged by fibrils [2].

Craze propagation can manifest itself in different forms, among others, the main ones are: stress cracking (widen by drawing) and environmental stress cracking (craze tip advanced). Stress cracking and environmental stress cracking of polymer are of major importance in the practical use of these materials since they led to the breakdown or failure of plastic materials. A plastic part needs to endure its entire designed life before it fails. Generally stress cracking and environmental stress cracking may occur in amorphous polymers like PVC and PMMA as well as in semi-crystalline polymers as PP and PE [9]. Stress cracking can be defined as an external or internal crack in a plastic caused by tensile stresses less than its short-term mechanical strength. Environmental stress cracking can be defined as the failure due to continuously acting external and/or internal stresses at about room temperature in the presence of surface active agents. This surface active agents do not cause any degradation of the polymer or do not chemically attack the polymer or produce any other effect but they accelerate the processes of microscopic brittle-crack formation [10] [11]. The surface active agents include all liquids which contain organic liquid like hydrocarbons, halogenated, ketones, aldehyde, esters, nitrogen and sulphur containing compounds. All of these liquids are absorbed by polymer in short time under simple immersion conditions. In such polymers, the crystallites are connected by tie molecules through the amorphous phase. The tie molecules play important role in the mechanical properties of the polymer through the transmission of load. The surface active agents act to lower the cohesive forces which maintain the tie molecules in the crystallites, thus facilitating their disentanglement and pull-out. This means that the surface active agents act as accelerating factor for crack propagation [10]-[12].

The testing temperature for craze propagation must be carefully chosen because of the recrystallization processes. Above certain temperatures the molecular arrangement of the resin under test can be altered and this leads to unrealistic results. The high temperature was used in slow craze as an accelerating variable for craze propagation [12].

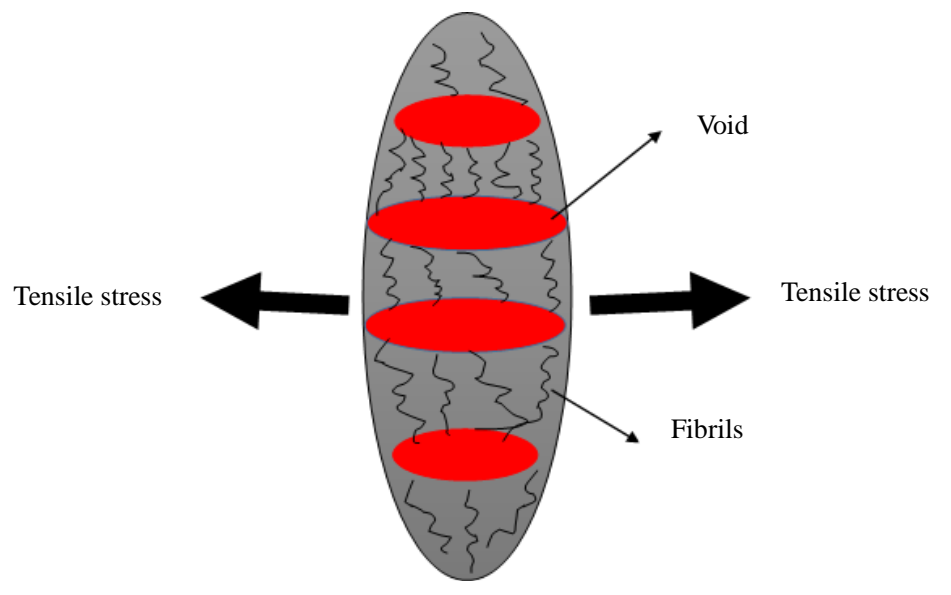

Figure 1. Schematic diagram for internal the structure of the craze. 
Many different techniques such as transmission electron microscope (TEM) [13], scanning electron microscope (SEM), low angle electron diffraction (LAED), small angle X-ray scattering (SAXS) [14] [15], optical microscopes [8] [16] and optical interference techniques [17]-[22], were used to study the crazing behavior of polymers. These experimental techniques were considered as useful methods to investigate and quantify the craze microstructure. Interference technique has been used as a major tool or direct observation of craze growth in transparent polymers. A fringe pattern can be observed as a result of interference of two beams, one is reflected from the lower surface of the craze and the other is reflected from the upper surface [20]-[22]. Wenbo Luo and Wenxian Lui [8] studied the effect of the stress intensity and time dependence on the areal craze density value of PMMA polymer by using optical microscope, mechanical stretching device and CCD camera. They found that there are direct proportionality between the stress intensity and the areal craze density of PMMA polymer. Schirrer et al. [23] estimated the toughness as a function of crack speed for PMMA polymer and investigated local properties such as craze fibril stress and fibril life time. Also they studied the craze length as a function of loading rate using optical interferometry technique. Many authors [11] [12] studied the effect of temperature on the crack propagation for different polymers like PMMA and PC at constant stress. It was found that by raising the environmental temperature, the crack propagation increases.

This article aims to follow the crazes that occur on the surface of stretched polypropylene fibres under different stretching conditions. In situ observations of the crazes will be made using Pluta polarizing interference microscope in its uniform field and fringe field modes. The relation between the areal craze density and the mean birefringence values of crazed PP fibres will be investigated. Optical images are recorded by a CCD camera and then processed by special image analysis software.

\section{Material and Methods}

Polypropylene (Basell Polyolefins product) filaments/fibres were fabricated, in the university of Leeds, UK. The advantage of this material is its good mechanical properties. In this work the immersion liquid used was a mixture from paraffin and alpha brome naphthalene with refractive index $1.4992 \pm 10^{-4}$ at $18^{\circ} \mathrm{C}$. The chemical structure of alpha brome naphthalene liquid is shown in Figure 2. This structure contains two aromatic ring and halogenated element, so this liquid can act as surface active agent. The Pluta double refracting, polarizing interference microscope [24] [25] was used. The Pluta microscope was fitted with a computerized unit consists of a CCD camera, PC computer, and digital monitor.

To study the craze propagation after stretching the fibre (cold drawing), the automatic stretching device [26] attached with the Pluta polarizing microscope [24] [25] has been used as shown in Figure 3. This automatic stretching device which consists of two stepper motors, rotating in reverse directions to produce extension with a fixed sample length. The fibre is fixed between the centers of the motors of diameter $\mathrm{d}$ separated by a distance $\mathrm{L}$ and rotated with an angular velocity $\omega$. This produces a linear velocity $v=d \omega$ and constant strain rate $\bar{e}=\mathrm{v} / \mathrm{L}$. The motors were controlled using a suitable interfacing circuit connected to the parallel port of the PC and driven using software designed for the purpose of controlling the two stepper motors, and recording the various strain values in their real time during the stretching process. The effect of stretching temperature was studied using a heating unit which consists of heater, heat sensor and temperature controller as shown in Figure 3.

\section{Experimental Results and Discussions}

Two-beam polarizing interference Pluta microscope (in its fringe field and uniform field modes) [24] [25] with the aid of stretching device [26] and CCD camera as shown in Figure 3 was used to carry out the experimental

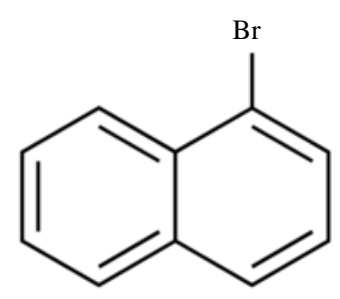

Figure 2. The chemical structure of the alpha brome naphthalene. 


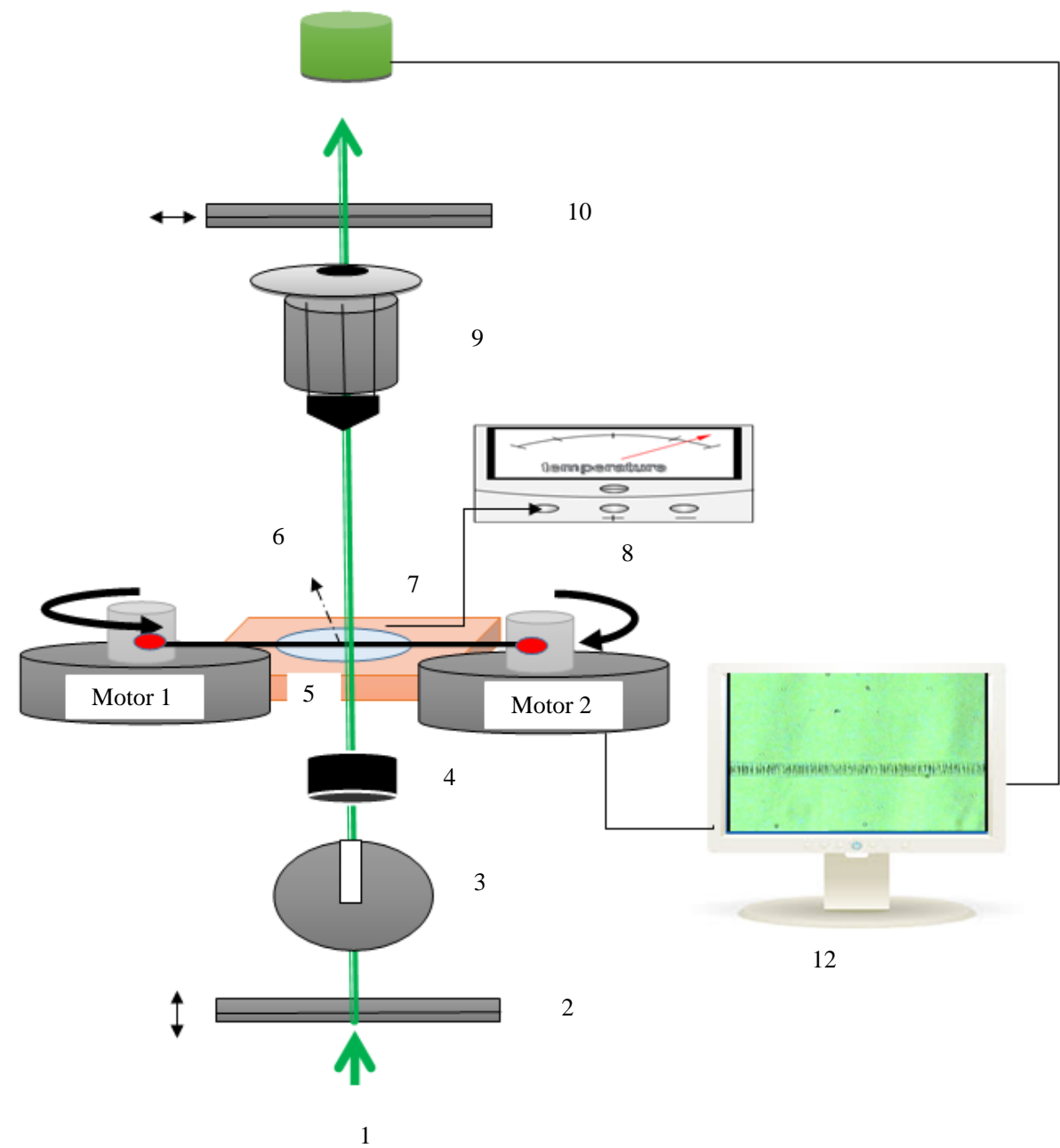

Figure 3. Schematic diagram for the modified automatic stretching device attached to heating unit and Pluta polarizing microscope. 1-monochromatic light, 2-polarizer, 3-slit diaphragm, 4-condenser, 5-heater, 6-fibre, 7-heat sensor, 8-temperature controller, 9-objective lens, 10-analyzer, 11-CCD camera, 12-PC computer. Reference [26].

work. Polypropylene fibres were strained with constant rate at room temperature $\left(18^{\circ} \mathrm{C}\right)$ until crazing initiated, and then the drawing of the fibre was stopped. The craze propagation was recorded using the CCD camera. Video images were used to calculate the craze velocity. To obtain results with high accuracy, uniform field mode of the Pluta microscope was used for in-situ observations and monitoring the crazes to avoid similarity between the crazes and dark fringes that occur in case of using fringe field mode.

\subsection{Estimation of Areal Craze Density with Different Stretching Speed of PP Fibres Using a Microscopic Image Analysis System (MIAS)}

Figures 4(a)-(e) present transmission optical micrographs captured with Pluta microscope in uniform field mode, with the aid of CCD camera, for samples of PP fibers at the moment of initial appearing of crazes for stretching speed values $0.35,0.41,0.45,0.52$ and $0.66 \mathrm{~cm} / \mathrm{sec}$, respectively. Monochromatic light of wavelength $\lambda=546$ $\mathrm{nm}$ was used at room temperature $18^{\circ} \mathrm{C}$. Generally all the images (a)-(e) show that the crazes form with their plane normal to the stretching direction. The areal craze density, which is defined as the ratio of the crazed area to the whole image area, was determined according to the procedures of image processing given by Luo and Liu [8]. The calculated areal craze densities are shown as a function of drawing speed in the plot of Figure 5. 
(a)

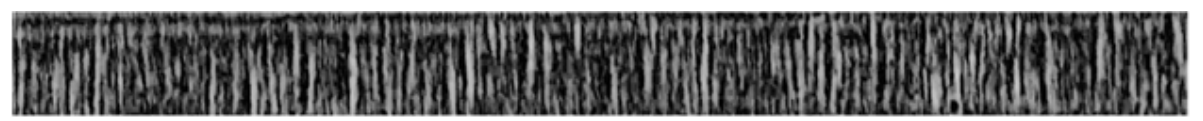

(b)

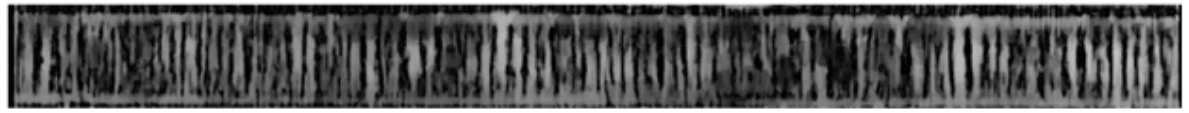

(c)

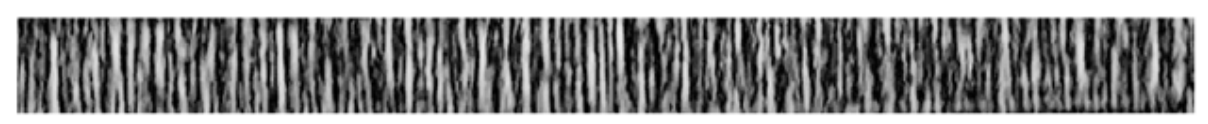

(d)

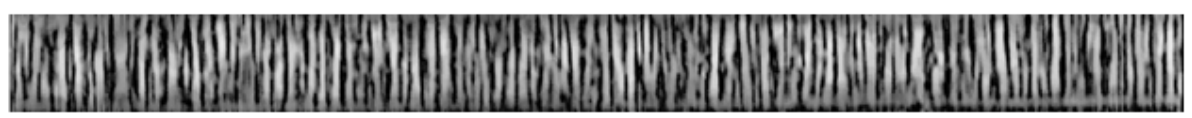

(e)

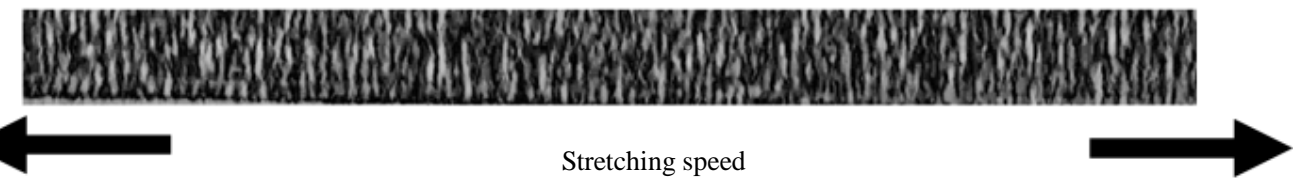

Figure 4. (a)-(e) presents transmission optical micrographs for samples of PP with stretching speed values $0.35,0.41,0.45,0.52$ and $0.66 \mathrm{~cm} / \mathrm{sec}$, respectively.

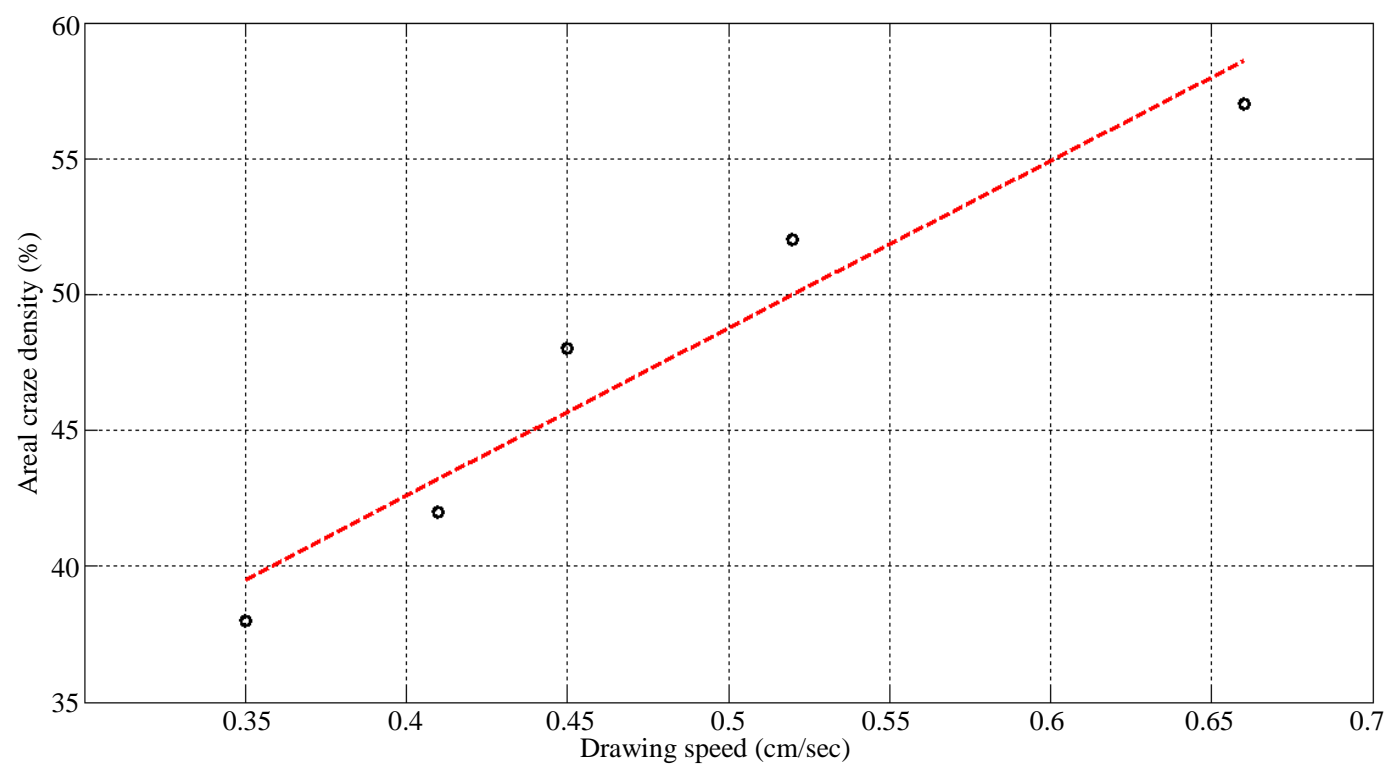

Figure 5. The areal craze density as a function of drawing speed for PP fibres.

From this figure it was observed that, for a fixed stretching time, the areal craze density increases with increasing the stretching speed. These results can be explained as follows: for relatively high stretching speed, the ability of the deformed molecular structure to dissipate the exerted work decreases due to the rapid deformation of the molecular chains. On the other hand, at low stretching speed, the slowly deformed chains allow the exerted energy to dissipate through the entire chain structure of the stretched fibre. The undissipated energy at high stretching speeds is localized and contributes the creation of craze sites, which increases the areal craze density 
[8] [27].

\subsection{Estimation of Craze Propagation Velocity and Deceleration with Different Stretching Speed of PP Fibres Using a Microscopic Image Analysis System (MIAS)}

Using Pluta interference microscope in its uniform field mode attached with automatic stretching device, the optical micrographs for crazed fibres at different stretching conditions durations were recorded using a CCD camera. Video images were used to calculate the craze propagation velocity. Figures 6(a)-(k), Figures 7(a)-(k), Figures 8(a)-(k), Figures 9(a)-(k) and Figures 10(a)-(k) show binary optical micrograph for craze propagation with stretching speed values $0.35,0.41,0.45,0.52$ and $0.66 \mathrm{~cm} / \mathrm{sec}$, respectively. This is achieved through the test durations $0,20,40,60,80,100,120,140,160,180$ and 200 sec., respectively. Monochromatic light of wavelength $\lambda=546 \mathrm{~nm}$ was used at room temperature $18^{\circ} \mathrm{C}$.

Figures 6(a)-(k) to Figures 10(a)-(k) clarify that the crazes propagate with different velocities depending on the stretching speed at room temperature $18^{\circ} \mathrm{C}$. The crazes propagation may occur due to two forces: stress craze and environmental stress craze of the immersion liquid contain alpha brome naphthalene which acts as surface active agents. And it reduces the cohesive forces which keep the tie molecules in the crystallites, thus facilitating their pull-out and disentanglement. This means that the surface active agents act as accelerating factor [9]-[11]. The crazes propagation velocities were calculated for stretching speed values which mentioned earlier. The effect of increasing the stretching speed was done to decrease the crazes propagation velocities as shown in Figure 11. This means that the areal craze density may acts as decreasing factor for the craze propagation. Also Figure 11 clarifies that for fixed value of drawing speed, the craze propagation velocity decreases with the test time.

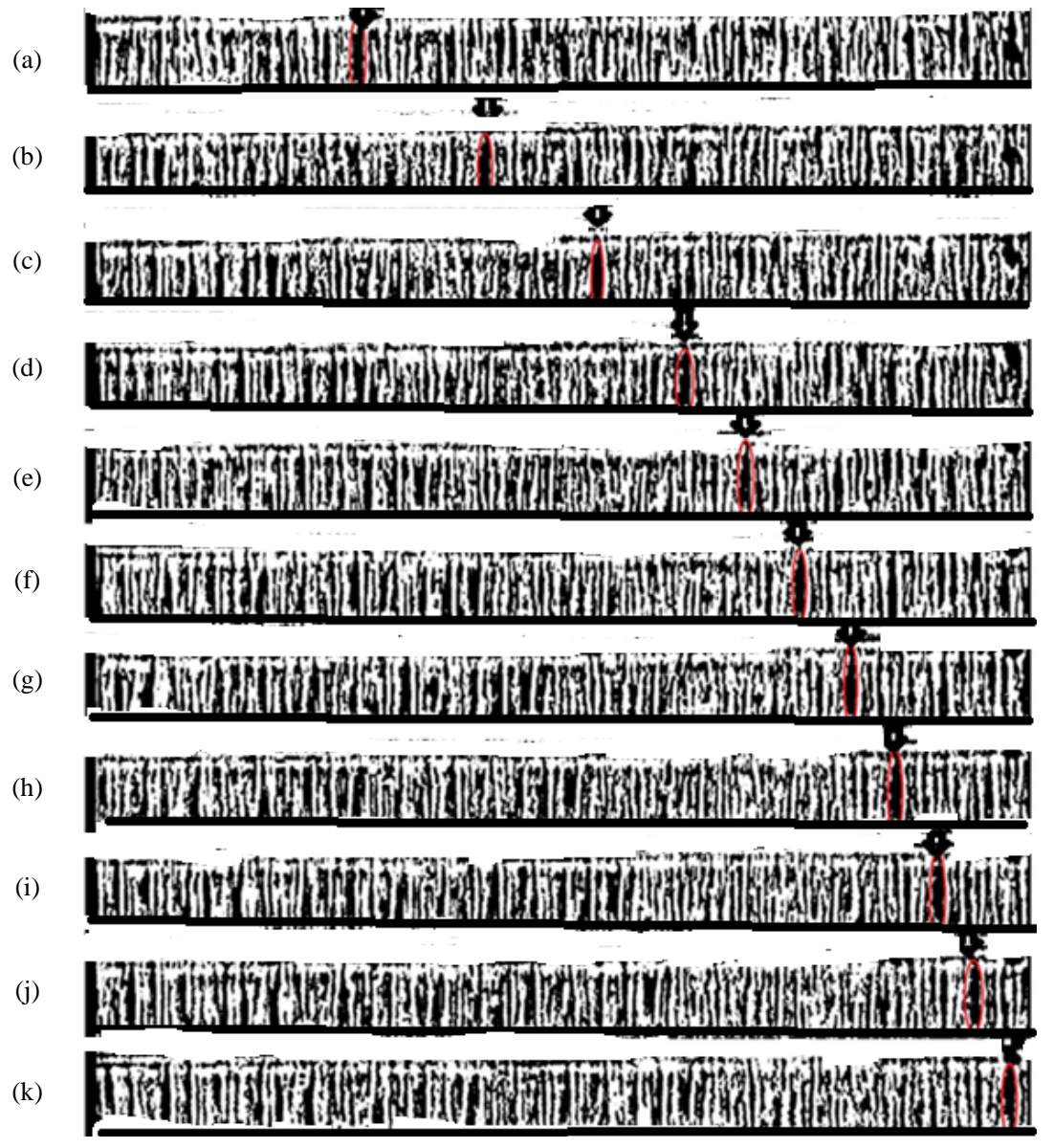

Figure 6. (a)-(k) Binary transmission optical micrographs for craze propagation with stretching speed value $0.35 \mathrm{~cm} / \mathrm{sec}$ through the durations $0,20,40,60,80,100,120$, 140, 160, 180 and $200 \mathrm{sec}$, respectively. 


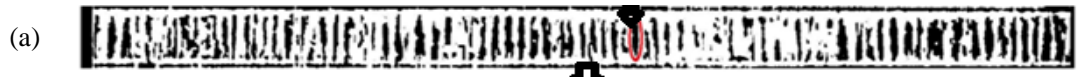

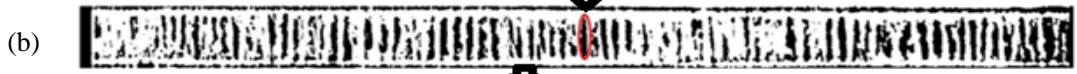

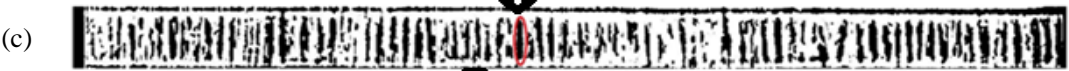
.

(d)

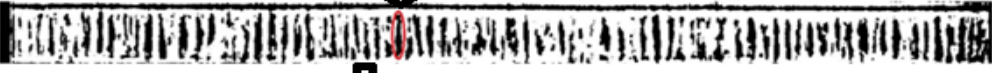
,

(e)

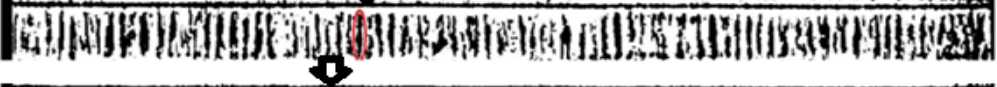
Hoilow

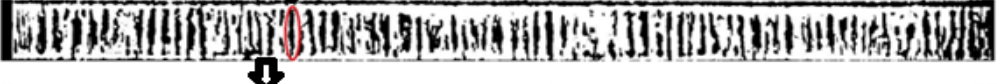

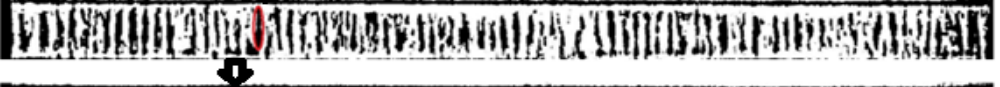

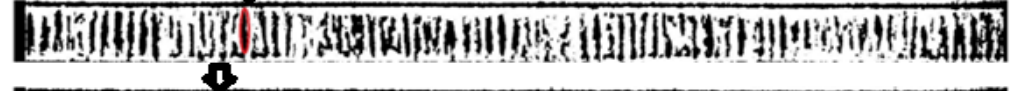

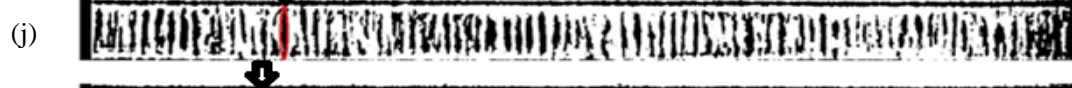

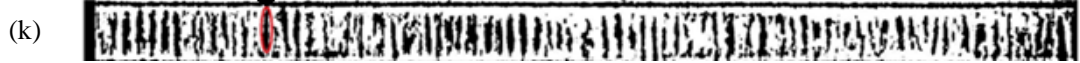

Figure 7. (a)-(k) Binary transmission optical micrographs for craze propagation with stretching speed value $0.41 \mathrm{~cm} / \mathrm{sec}$ through the durations $0,20,40,60,80,100,120$, $140,160,180$ and $200 \mathrm{sec}$, respectively.

(a)

(b)

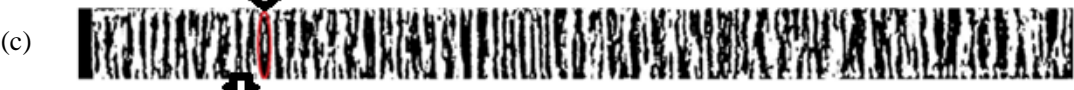

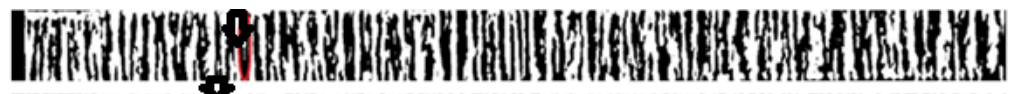

1) Min

(d)

(e)

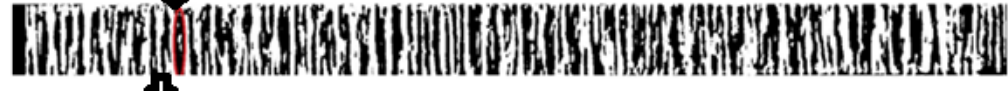

e)

D.

(f)

(g)
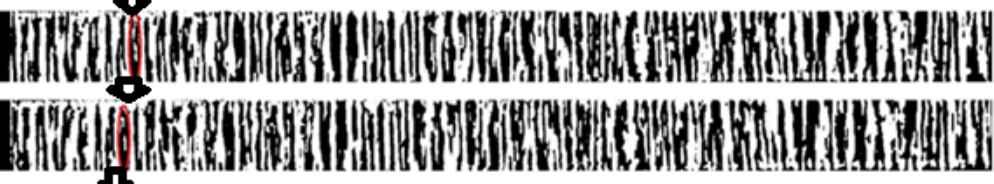

(h)

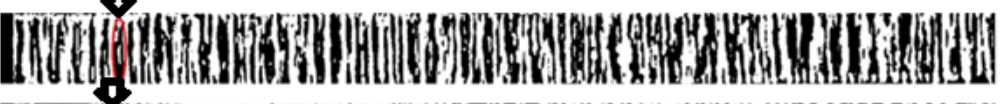

(i)

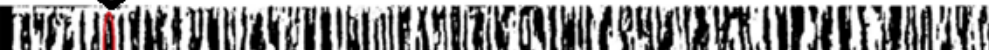

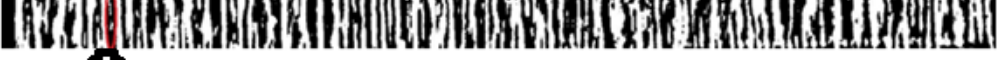

A6

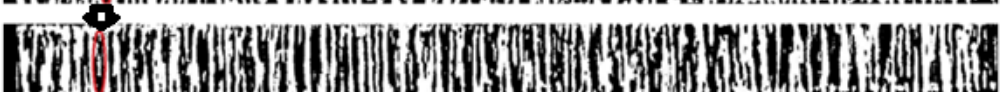

(k)

Figure 8. (a)-(k) Binary transmission optical micrographs for craze propagation with stretching speed value $0.45 \mathrm{~cm} / \mathrm{sec}$ through the durations $0,20,40,60,80,100,120$, 140, 160, 180 and $200 \mathrm{sec}$, respectively. 


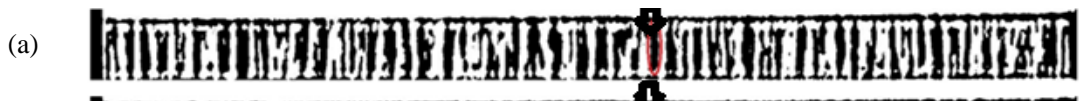

(5) Villy

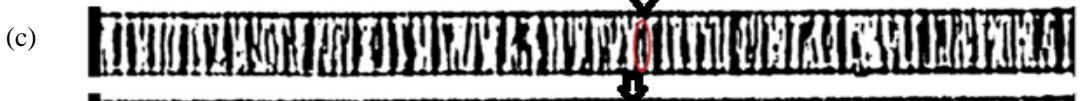

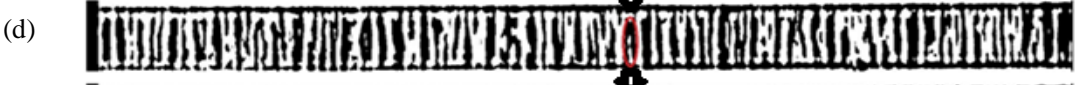

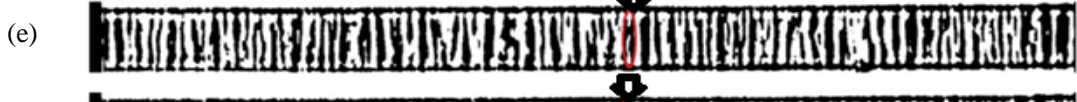

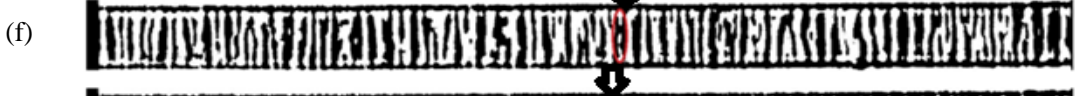

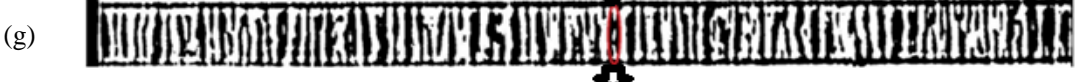

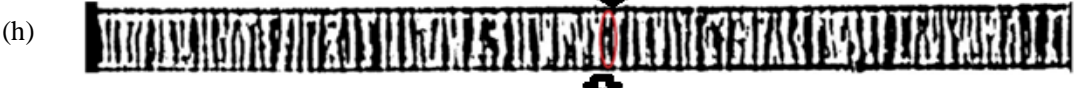

(i)

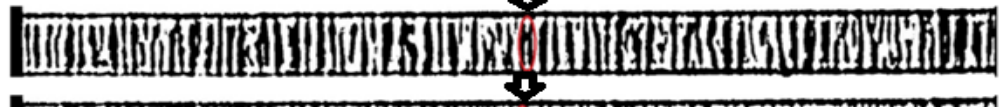

(j)

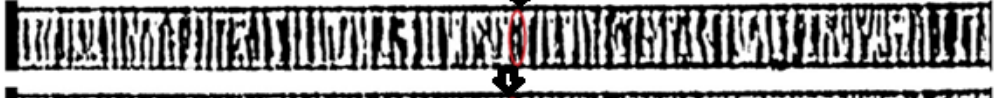

(k)

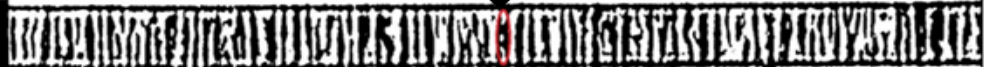

Figure 9. (a)-(k) Binary transmission optical micrographs for craze propagation with stretching speed value $0.52 \mathrm{~cm} / \mathrm{sec}$ through the durations $0,20,40,60,80,100,120$, 140, 160, 180 and $200 \mathrm{sec}$, respectively.

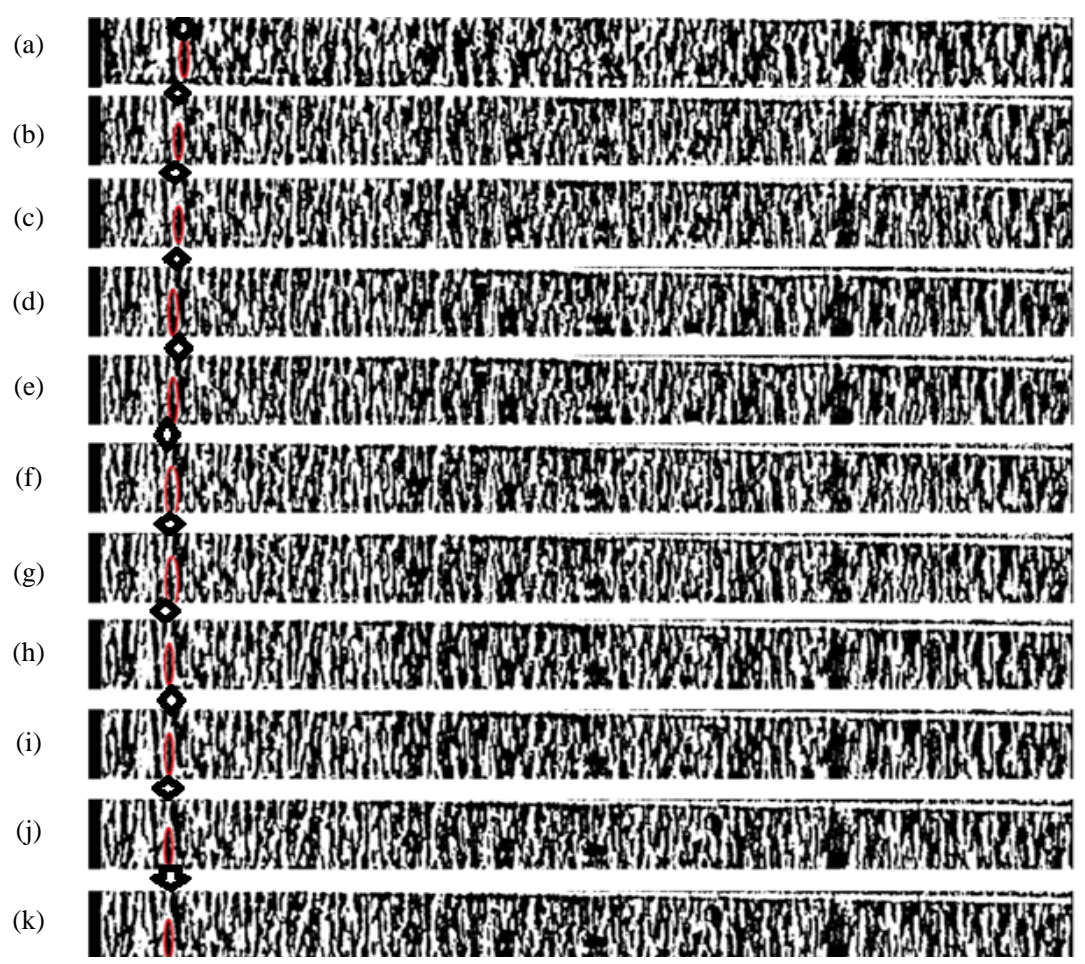

Figure 10. (a)-(k) Binary transmission optical micrographs for craze propagation with stretching speed value $0.66 \mathrm{~cm} / \mathrm{sec}$ through the durations $0,20,40,60,80,100,120$, $140,160,180$ and 200 sec, respectively. 


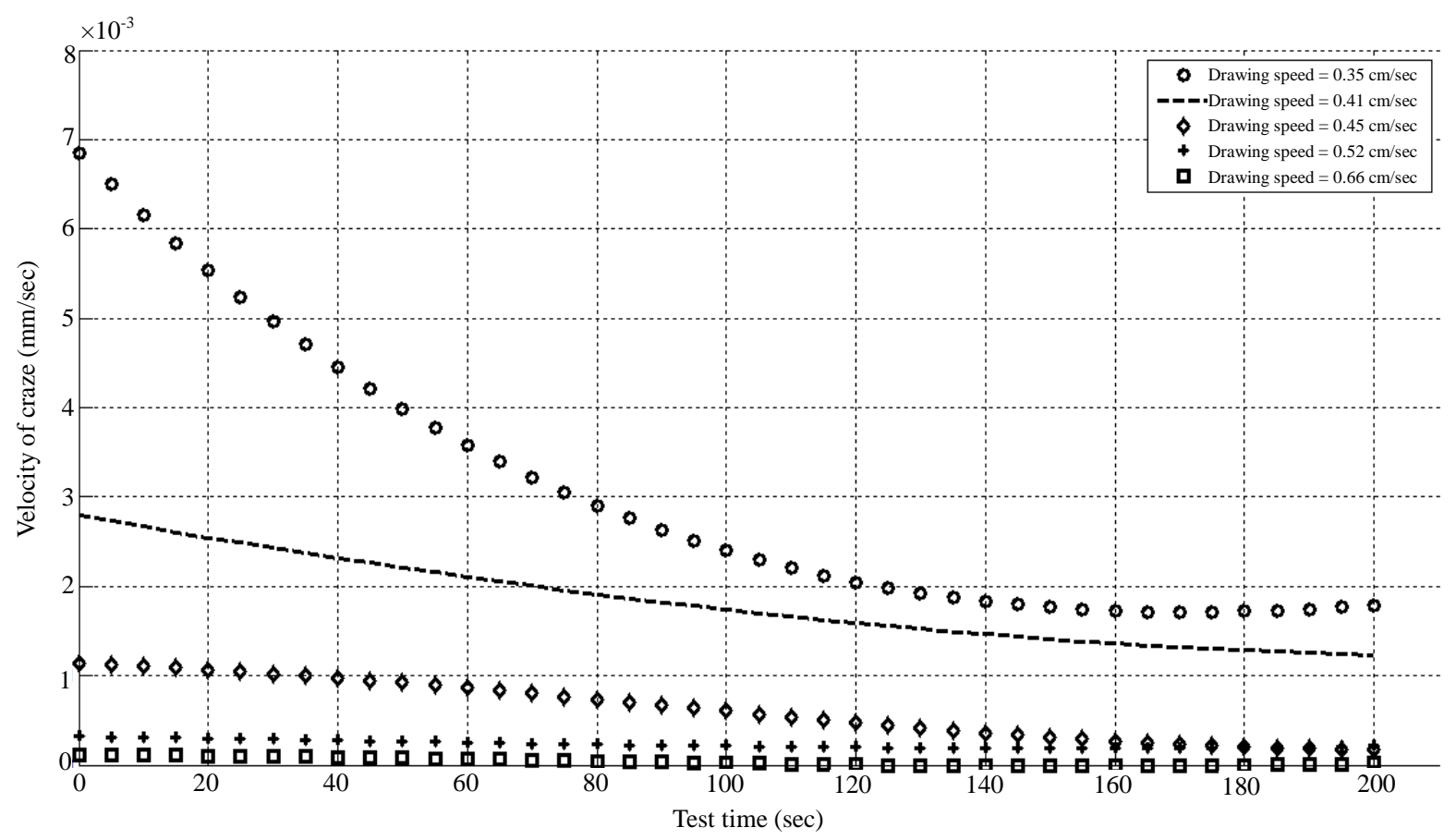

Figure 11. The craze propagation velocity as a function of time at different stretching speed values $0.35,0.41,0.45,0.52$ and $0.66 \mathrm{~cm} / \mathrm{sec}$, respectively.

The deceleration " $a$ " can calculated as function with drawing speed by using the following equation:

$$
a=\frac{\mathrm{d} v}{\mathrm{~d} t}=\frac{v_{f}-v_{i}}{t_{f}-t_{i}}
$$

where $v_{i}$ is the initial velocity at initial time $t_{i}$ and $v_{f}$ is the final velocity at final time $t_{f}$. Figure 12 indicates that the deceleration decreases with increasing the drawing speed or (craze density). Where application of external stress as consequence of mechanical stretching causes the molecular chains to be directed towards the axial direction. Moreover, extension of the molecular chains occurs upon further stretching, and eventually rupture occurs at different sites creating voids. Furthermore the coalescence voids forms a craze which propagates the sample during the application of stress at a velocity depending on the value of the applied stress. On the other hand, the propagating crazed sites continue its motion even if the stress is removed due to its inertia. This behavior observed as decelerated crazes motion upon sudden removed the stress which lasts for several minutes. This deceleration phenomenon depends on two factors. The first one is due to the environmental stresses which amount the surface active agents are volatized with time. This factor did not show much contribution to the deceleration of crazes. The second factor is the inertia of the moving fibril-void structures, i.e. crazes and it is considered the dominate factor contributing to the deceleration phenomenon observed during the sudden removed of the applied stress. The friction of the decelerated crazes with the internal structure of the stretched polymers decreases the velocity until the craze stops after several minutes of decelerated motion.

\subsection{The Effect of the Craze Dimension on the Their Propagation Velocity at Constant Stretching Speed of PP Fibres Using a Microscopic Image Analysis System (MIAS)}

Owing to the fact that the maximum thickness of the craze has been previously used as a fracture criteria [28]. The effect of craze dimensions on their propagation velocity was studied. Figures 13(a)-(g) show crazes which differ in their dimensions for stretched PP fibre at constant stretching speed $0.41 \mathrm{~cm} / \mathrm{sec}$. This Figure was used to study the effect of the crazes dimensions on their propagation velocity by tracking five different crazes marked as numbers I, II, III, IV and V, respectively, during the durations 0, 10, 20, 30, 40, 50 and 60 sec, respectively. The five crazes were monitored during their propagation. 


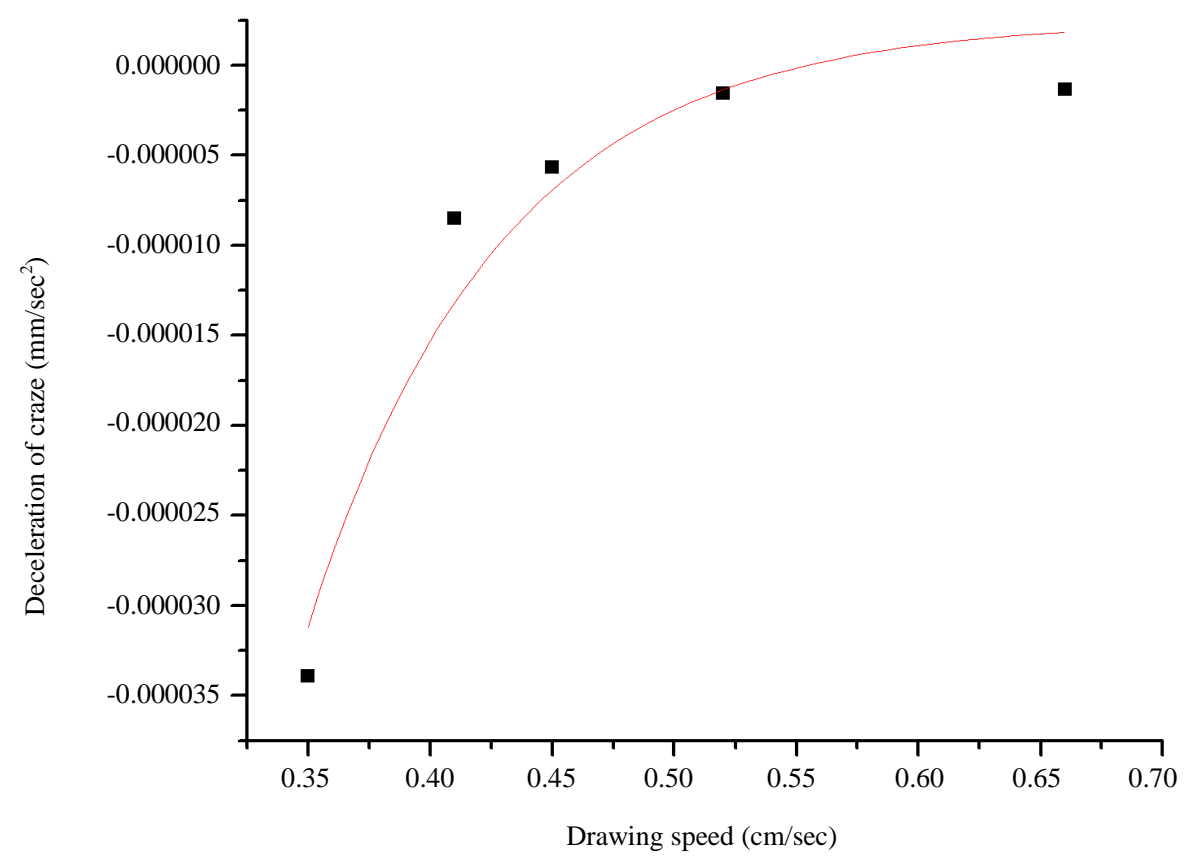

Figure 12. Deceleration of craze propagation as a function of drawing speed for PP fibres.

(a) IIS

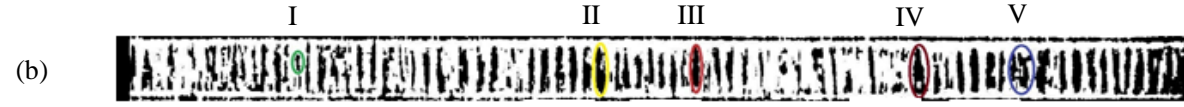

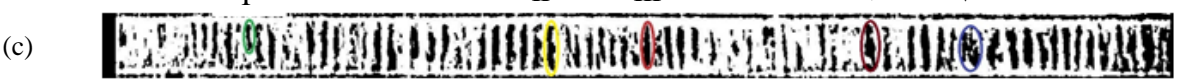
I II III IV I

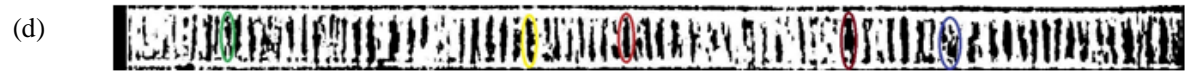

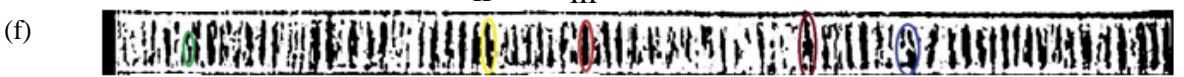

(f) $\begin{array}{lllll}\text { I } & \text { II } & \text { III } & \text { IV } & \text { V }\end{array}$ Hob I II III $\quad$ IV V

(g)

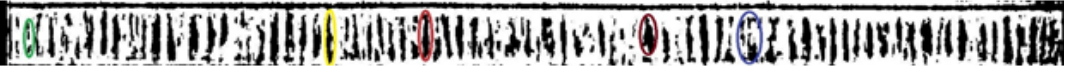

Direction of crazes propagation

Figure 13. (a)-(g) shows the propagation of five crazes with stretching speed value 0.41 $\mathrm{cm} / \mathrm{sec}$ during the duration $0,10,20,30,40,50$ and $60 \mathrm{sec}$, respectively.

Using the filled contour method [29] with magnification 10×, the filled contours of crazes for fixed test duration $10 \mathrm{sec}$ are presented in Figures 14(a)-(e). The estimated areas of the crazes were found to be 5.52, 11.32, 15, 17.02 and $22.22 \mu \mathrm{m}^{2}$, respectively. Figure 15 shows the relation between the propagation velocity of the crazes and their areas at constant test duration $10 \mathrm{sec}$. This Figure clarifies that the craze dimension has no effect on craze propagation velocity at room temperature $18^{\circ} \mathrm{C}$. 


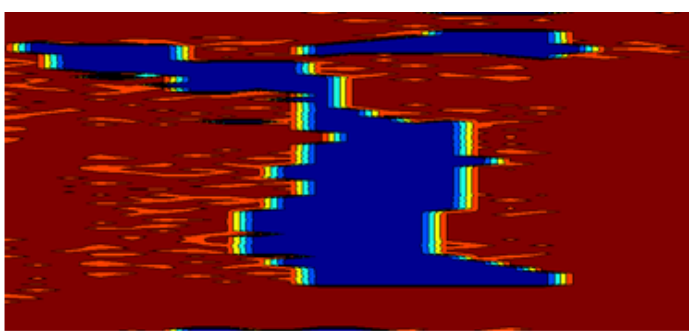

(a)

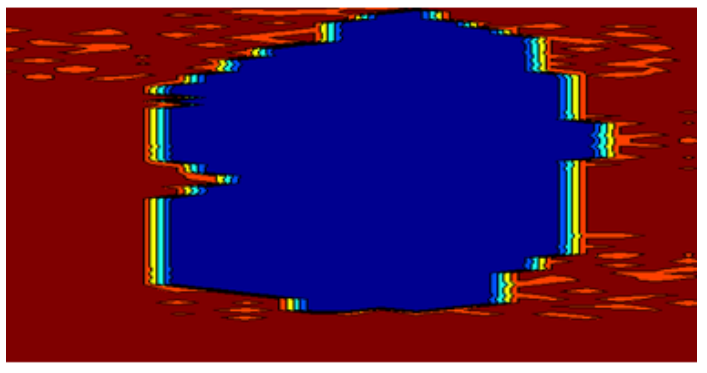

(c)

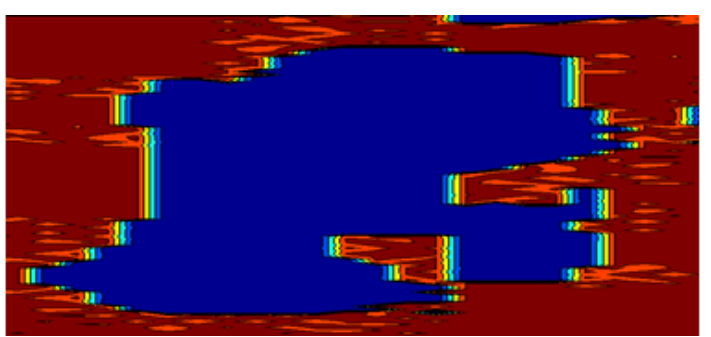

(b)

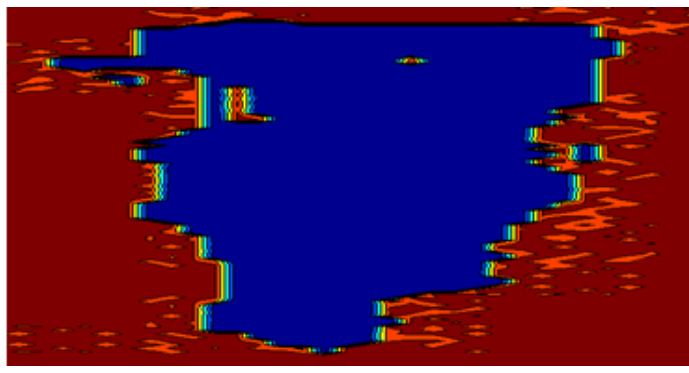

(d)

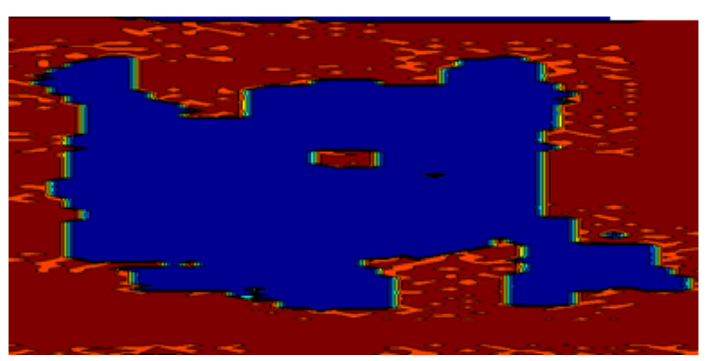

(e)

Figure 14. (a)-(e) shows the filled contour images of five crazes with stretching speed value $0.41 \mathrm{~cm} / \mathrm{sec}$.

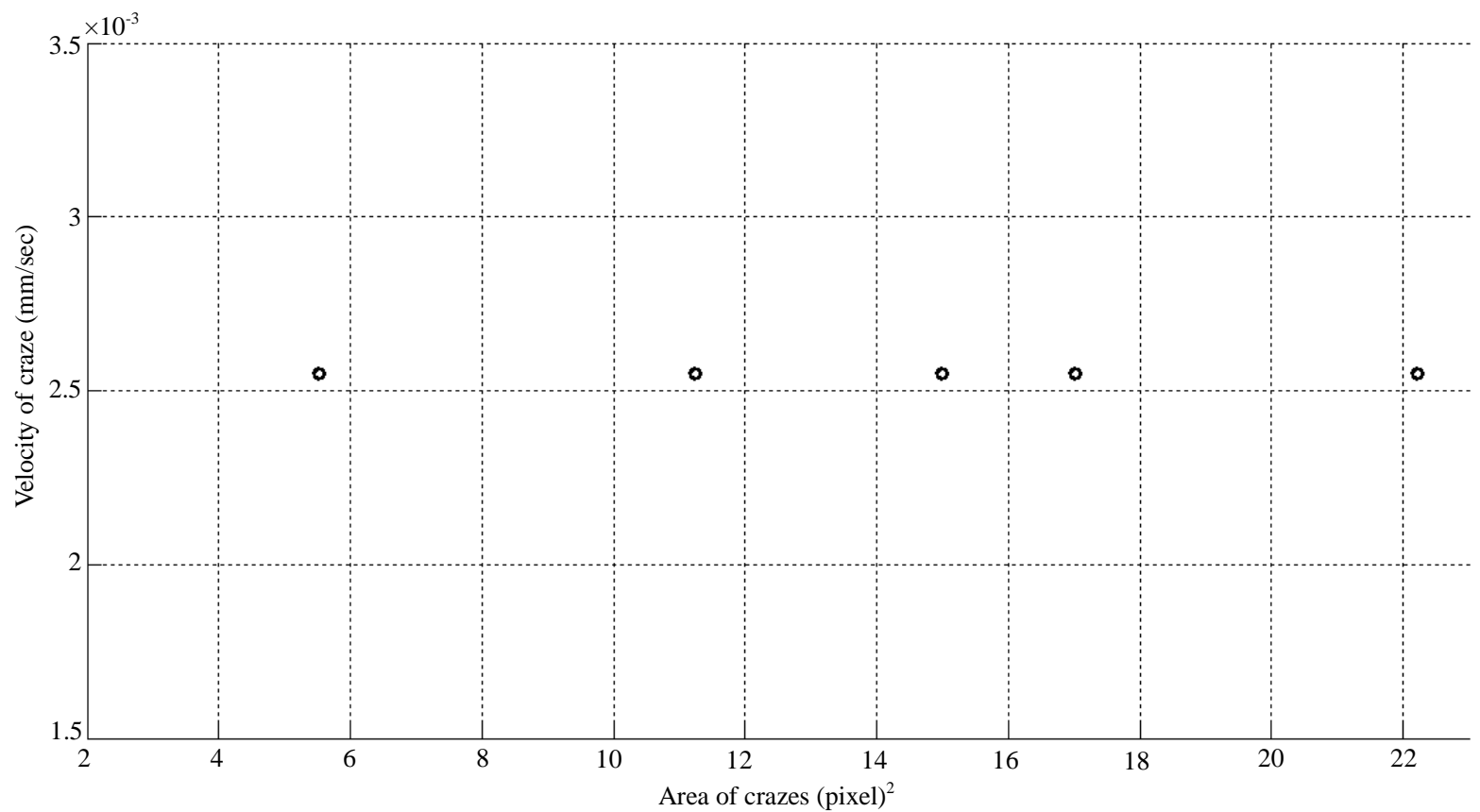

Figure 15. The craze propagation velocity as a function of area of different crazes at constant duration 10 sec. 


\subsection{The Effect of the Temperature on the Craze Propagation Velocity at Constant Stretching Speed of PP Fibre Using a Microscopic Image Analysis System (MIAS)}

Williams and Marshall [30] have studied the effect of temperature on the craze propagation in different number of polymers. From experience, it has well demonstrated that temperatures act as accelerating deformation processes. In this work, the temperature of stretched PP fibres was raised gradually from $15^{\circ} \mathrm{C}$ to $60^{\circ} \mathrm{C}$ using the heating unit shown in Figure 3. Figures 16(a)-(j) present the binary optical micrographs showing craze propagation for stretching speed value $0.41 \mathrm{~cm} / \mathrm{sec}$ at test temperatures $15^{\circ} \mathrm{C}, 20^{\circ} \mathrm{C}, 25^{\circ} \mathrm{C}, 30^{\circ} \mathrm{C}, 35^{\circ} \mathrm{C}, 40^{\circ} \mathrm{C}, 45^{\circ} \mathrm{C}$, $50^{\circ} \mathrm{C}, 55^{\circ} \mathrm{C}$ and $60^{\circ} \mathrm{C}$, respectively. The crazes propagation velocities at stretching speed values 0.41 and 0.45 $\mathrm{cm} / \mathrm{sec}$, respectively through the previously mentioned temperatures are estimated and represented in Figure 17. From this figure it is noticed that at low temperatures from $15^{\circ} \mathrm{C}$ to $40^{\circ} \mathrm{C}$, there are slight increasing in the craze propagation velocity. On the other hand at higher temperatures from $45^{\circ} \mathrm{C}$ to $60^{\circ} \mathrm{C}$ the velocity of craze propagation multiplies several times. This clarifies the effect of temperature as accelerating factor which appears at high temperatures. This can be explained as: upon the raising temperature, the mobility of the molecular chains increases consequently, fibril voids structure of crazes began to flow. The increased flow of crazes is observed as increasing in its propagation velocity. Accordingly, increasing the test temperature results a faster propagation of crazes. Moreover, increasing the stretching speed results, a more flexible molecular chain which resist the propagation of crazes inside the structure of the drawn fibres. Accordingly, the stretched fibres require high temperature in order to increase the propagation speed of the crazes. This is in a good agreement with the obtained results shown in Figure 17. Owingto the drawing speed, the temperature required to accelerate the craze propagation increases with the craze density, taking into account that above a certain high temperature, the recrystallization process will occur [12].

\subsection{D Birefringence Profile and the Mean Birefringence of Crazed PP Fibres}

The samples of PP fibres were stretched with the stretching device [26] to initiate crazes and observed directly

(a)

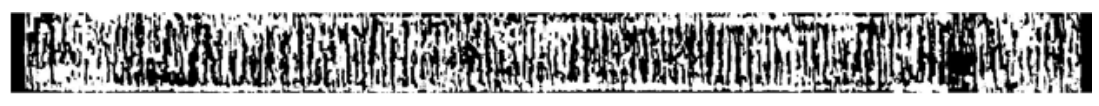

(b)

(c)

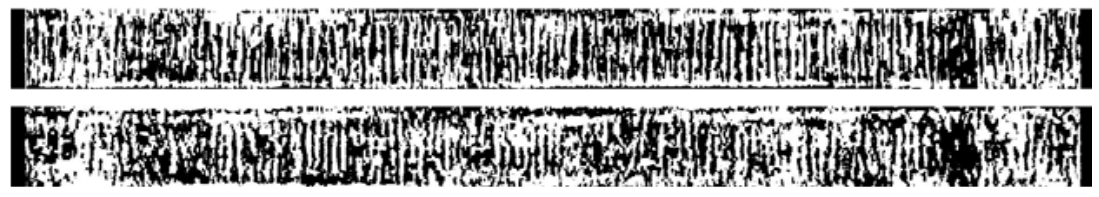

(d)

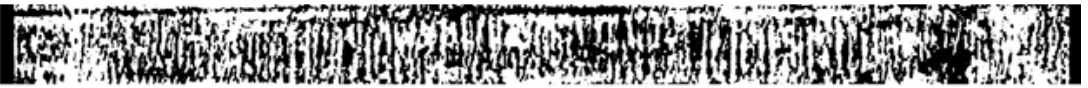

(e)

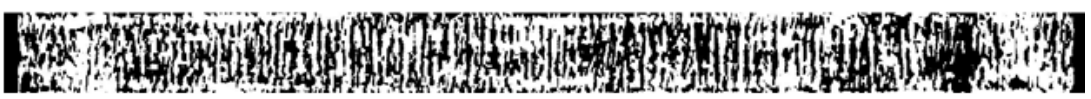

(f)

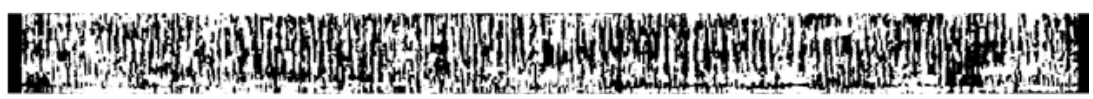

(g)

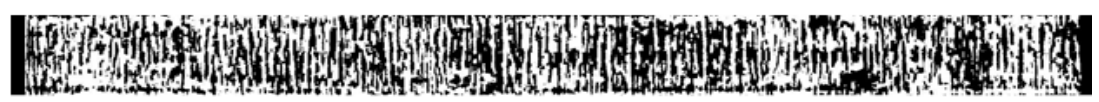

(h)

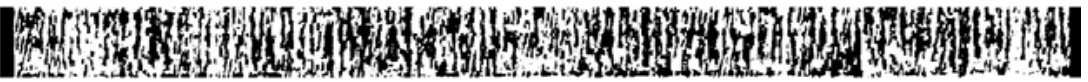

(i)

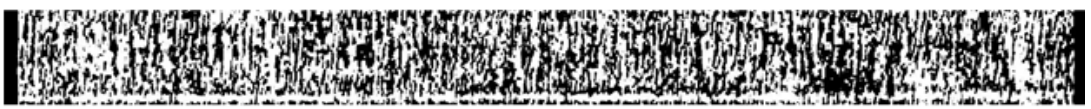

(j)

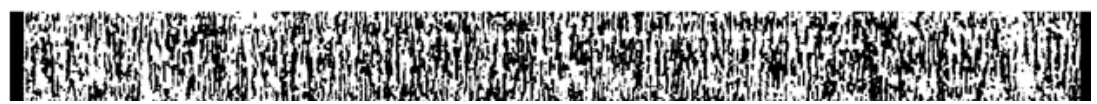

Figure 16. (a)-(j) The binary transmission optical micrographs for craze propagation with stretching speed value $0.41 \mathrm{~cm} / \mathrm{sec}$ at temperatures $15^{\circ} \mathrm{C}, 20^{\circ} \mathrm{C}, 25^{\circ} \mathrm{C}, 30^{\circ} \mathrm{C}, 35^{\circ} \mathrm{C}, 40^{\circ} \mathrm{C}, 45^{\circ} \mathrm{C}$, $50^{\circ} \mathrm{C}, 55^{\circ} \mathrm{C}$ and $60^{\circ} \mathrm{C}$, respectively. 
in the Pluta polarizing interference microscope in its fringe field mode. In this study, the areal craze density was calculated as a function of optical birefringence. Figures 18(a)-(e) show the non-duplicated microinterferograms captured with Pluta polarizing interference microscope for PP fibre stretched with fixed speed value $0.41 \mathrm{~cm} / \mathrm{sec}$ and their areal craze densities were $0 \%, 35 \%, 42 \%, 52 \%, 62 \%$, respectively. The birefringence profiles of this fibre using the non-duplicated image, taking into account the refraction of the incident beam by fibre layers given by the following equation [31]:

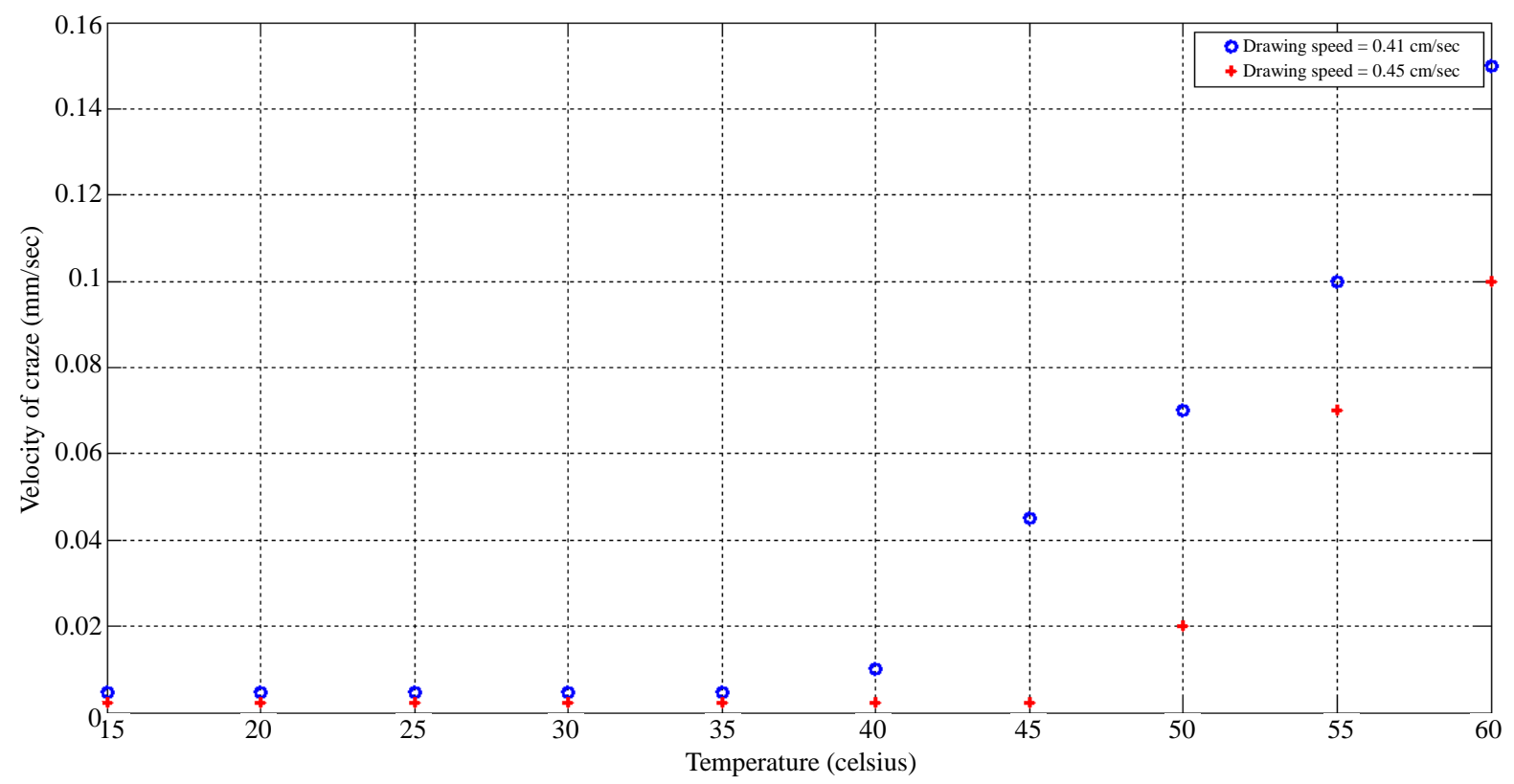

Figure 17. The craze propagation velocity as a function of temperature at stretching speed values 0.41 and, $0.45 \mathrm{~cm} / \mathrm{sec}$.
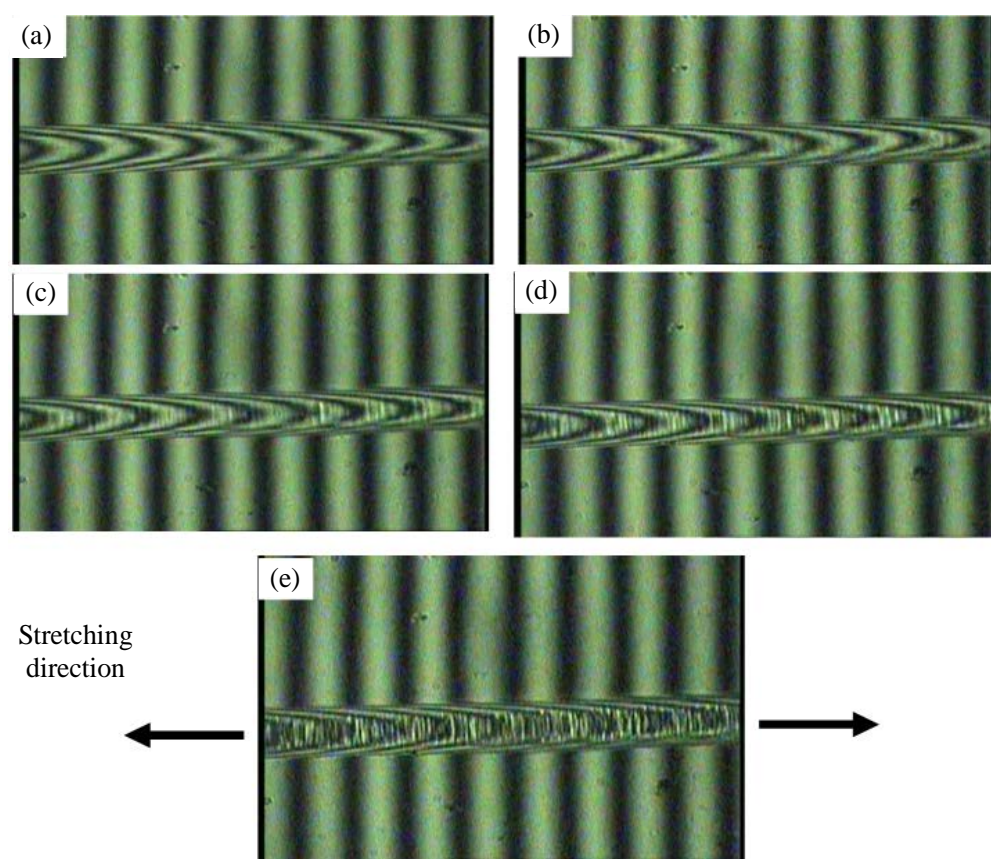

Figure 18. (a)-(e) shows the non-duplicated microinterferograms captured with Pluta polarizing microscope for a PP fibres stretched with speed value $0.41 \mathrm{~cm} / \mathrm{sec}$ with different areal craze densities $0 \%$, 35\%, $42 \%, 52 \%, 62 \%$, respectively. 


$$
\Delta n_{Q}=\left[\frac{1}{R-(Q-1) t}\right]\left[\frac{\lambda \Delta z_{Q}}{2 b}-t \sum_{j=1}^{j=Q-1} \Delta n_{j}\right]
$$

where $R$ is the fibre radius, $Q$ is the layer number, $\mathrm{t}$ is the layer thickness $(t=R / Q), Z_{Q}$ is the shift of the fringes due to the presence of a phase object, $j$ is an integer runs from 1 to $(Q-1)$ and $b$ is the interfering spacing. The 3D birefringence profile for PP fibres was shown in Figures 19(a)-(e). In all of the 3D birefringence profiles, it was noticed that, the inner layers have the maximum birefringence values. Also, the birefringence values decrease

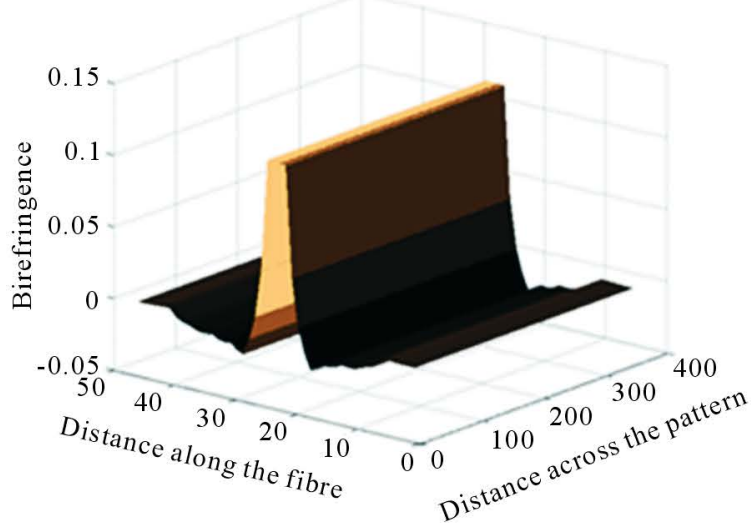

(a)

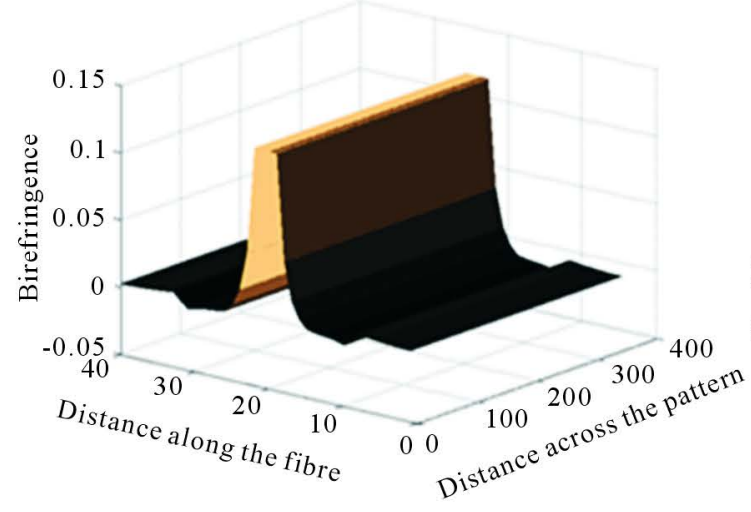

(c)

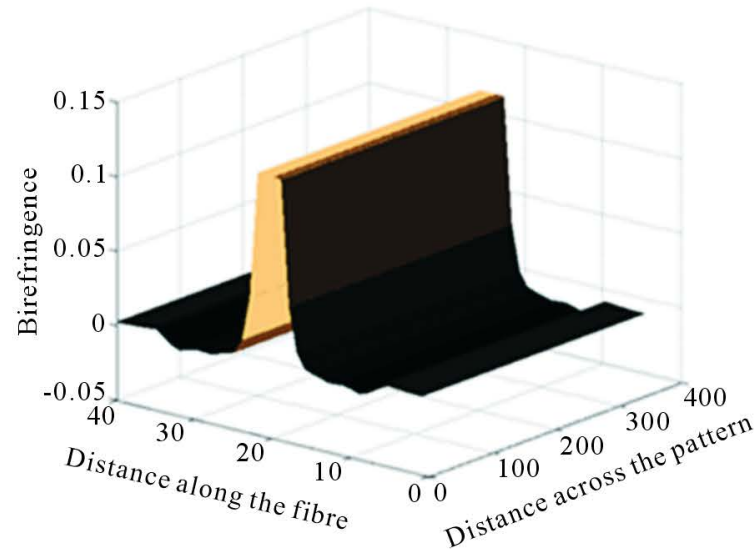

(b)

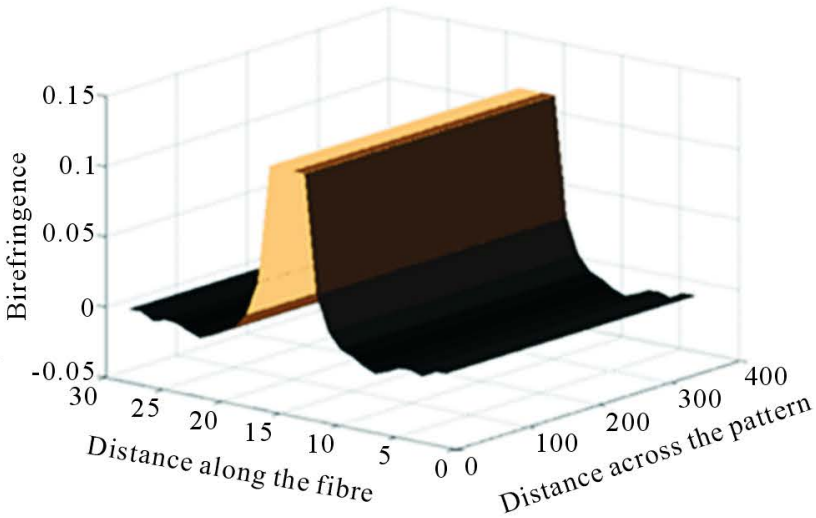

(d)

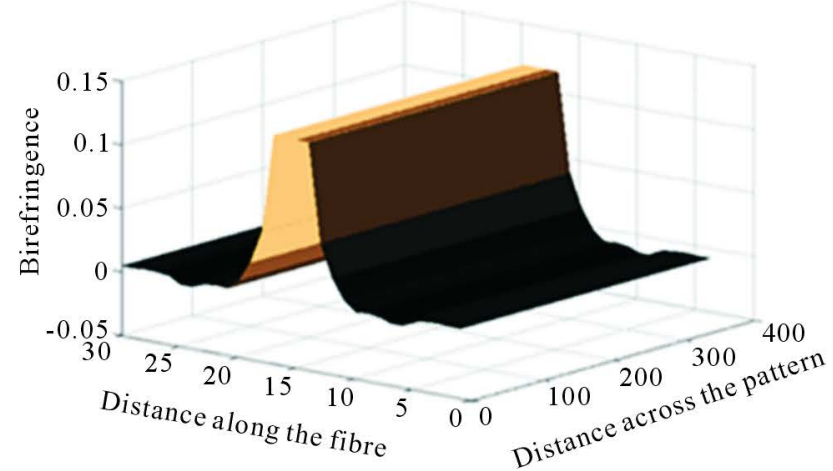

(e)

Figure 19. (a)-(e) shows the 3D birefringence profiles for a PP fibres stretched with speed value $0.41 \mathrm{~cm} / \mathrm{sec}$ with different areal craze densities $0 \%, 35 \%, 42 \%, 52 \%, 62 \%$, respectively. 
for the outer layers. This implies that, the maximum orientation of the molecular chains to the fibre axial direction was observed for the inner most layers. Consequently, mechanical stretching affects the inner layers of the fibre more than the outer layers. The mean birefringence value can be calculated by the following equation [32]:

$$
\Delta n=\frac{\Delta Z \lambda}{b t}
$$

Figure 20 shows the relation between the areal craze density and the mean birefringence values. From Figure 20 , it is clarified that, an increase of the orientation of the molecular chains was observed during the mechanical stretching of the fibre even in the presence of crazes.

\section{Conclusions}

Craze propagation in stretched polypropylene (PP) fibres was monitored and quantified during a mechanical stretching process, using two beam polarizing interference Pluta microscope with the aid of microscopic image analysis system (MIAS). The uniform field mode of the Pluta microscope was used for this purpose because in the fringe field mode the MAIS was affected by the dark fringes as well as the crazes leading to less accurate results. According to the obtained results, it was found that, the areal craze density increased with the increasing of the drawing speed. Also surface active agent alpha brome naphthalene, (the immersion liquid), is acted as an accelerating factors for craze initiation and propagation. The areal craze density and drawing speed are greatly influenced the propagation of crazes. The crazes do not propagate at uniform velocity in presence of the surface active agent, alpha brome naphthalene. Decelerate of crazes was observed. The areal craze density and drawing speed decelerated the propagation of crazes. Results showed that the craze propagation is a temperature dependent phenomena, i.e. raising the ambient temperature causes the crazes to propagate at high velocities. Also from the 3D birefringence profiles it was noticed that the mechanical stretching affects the inner layers more than the outer layers of the fibre.

Generally, the design of polymeric fibres with improved mechanical properties can lead to formation of undesired crazed structure. However, Pluta polarizing microscope was used to follow and monitor the crazes that occur on the surface of stretched polypropylene fibres in real time. This confirms the fact that, if a scanning electron microscope (SEM) is not available, polarizing light microscope can be applied with the aid of the microscopic image analysis system (MIAS) and usually provides satisfactory results.

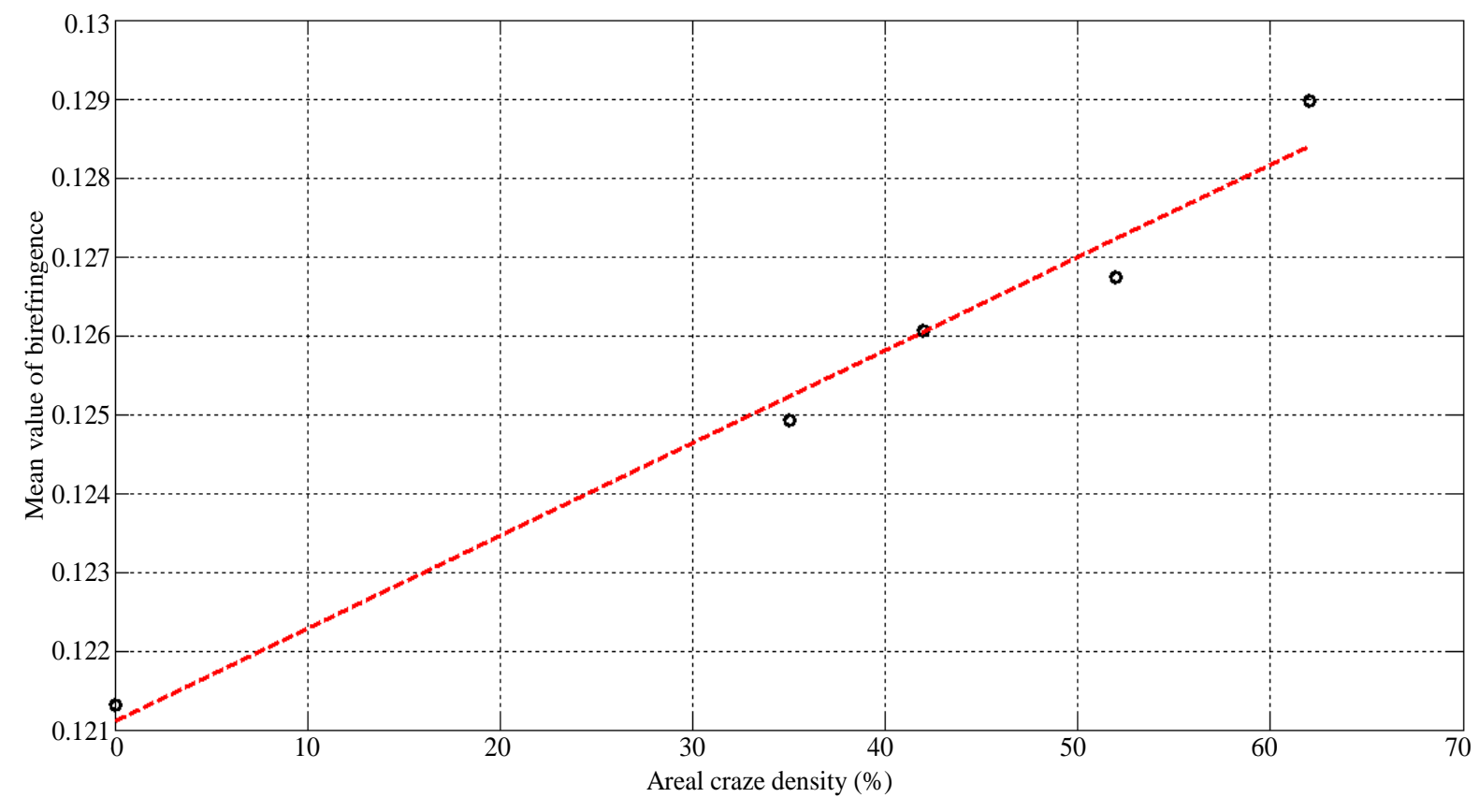

Figure 20. The mean value of birefringence as a function of areal craze density at fixed stretching speed value $0.41 \mathrm{~cm} / \mathrm{sec}$. 


\section{Acknowledgements}

We would like to express our deep thanks to Prof. Dr. A. A. Hamza, for his useful discussion and lending many facilities. And also to Dr. H. M. El-Desouky for his help to spin polypropylene fibre sing Fibre Extrusion Technology single screw extruder machine, University of Leeds, UK.

\section{References}

[1] Kambour, R.P. (1973) A Review of Crazing and Fracture in Thermoplastic. Journal of Polymer Science: Macromolecular Reviews, 7, 1-154. http://dx.doi.org/10.1016/S0032-3861(99)00234-7

[2] Marissen, R. (2000) Craze Growth Mechanics. Polymer, 41, 1119-1129.

[3] Courtenry, T.H. (2005) Mechanical Behavior of Materials. Waveland Press, Long Grove.

[4] Thomas, C., Ferreiro, V., Coulon, G. and Seguela, R. (2007) In Situ AFM Investigation of Crazing in Polybutene Spherulites under Tensile Drawing. Polymer, 48, 6041-6048. http://dx.doi.org/10.1016/j.polymer.2007.07.062

[5] Hui, C.Y., Ruina, A., Creton, C. and Kramer, E.J. (1992) Micromechanism of Crack Growth into a Craze in Polymer Glass. Macromolecules, 25, 3948-3955. http://dx.doi.org/10.1021/ma00041a018

[6] Kramer, E.J. (1983) Microscopic and Molecular Fundamentals of Crazing, Crazing of Polymers. Springer, Berlin.

[7] Donald, A.M. and Kramer, E.J. (1981) The Mechanism for Craze-Tip Advance in Glassy Polymers. Philosophical Magazine A, 43, 857-870.

[8] Luo, W. and Liu, W. (2007) Incubation Time to Crazing in Stressed Poly (Methyl Methacrylate). Polymer Testing, 26, 413-418. http://dx.doi.org/10.1016/j.polymertesting.2006.12.013

[9] Young, R.J. and Lovell, P.A. (1991) Introduction to Polymer. Chapman \& Hall, London. http://dx.doi.org/10.1007/978-1-4899-3176-4

[10] Qian, R., Lu, X. and Brown, N. (1993) The Effect of Concentration of an Environmental Stress Cracking Agent on Slow Crack Growth in Polyethylene. Polymer, 34, 4727-4731. http://dx.doi.org/10.1016/0032-3861(93)90708-I

[11] Ward, A.L., Lu, X., Huang, Y. and Brown, N. (1991) The Mechanism of Slow Crack Growth in Polyethylene by an Environmental Stress Cracking Agent. Polymer, 32, 2172-2178. http://dx.doi.org/10.1016/0032-3861(91)90043-I

[12] Wright, D.C. (1996) Environmental Stress Cracking of Plastics. Rapra Technology Ltd.

[13] Lauterwaster, B.D. and Kramer, E.J. (1979) Microscopic Mechanisms and Mechanics of Craze Growth and Fracture. Philosophical Magazine A, 39, 469-495. http://dx.doi.org/10.1080/01418617908239285

[14] Kambour, R.P. (1964) Structure and Properties of Crazes in Polycarbonateaned Other Glassy Polymers. Polymer, 5, 143-155. http://dx.doi.org/10.1016/0032-3861(64)90128-4

[15] Doll, W. (1983) Advances in Polymer Science. Springer, Berlin.

[16] Beardmore, P. and Rabinowitz, S. (1975) Craze Formation and Growth in Anisotropic Polymers. Journal of Materials Science, 10, 1763-1770. http://dx.doi.org/10.1007/BF00554938

[17] Brown, H.R. and Ward, I.M. (1973) Craze Shape and Fracture in Poly (Methyl Methacrylate). Polymer, 14, 469-475. http://dx.doi.org/10.1016/0032-3861(73)90152-3

[18] Pitman, G.L. and Ward, I.M. (1976) Effect of Molecular Weight on the Craze Shape and Fracture Toughness in Polycarbonate. Polymer, 20, 895-902. http://dx.doi.org/10.1016/0032-3861(79)90130-7

[19] Mills, N.J. and Walker, N. (1976) Craze Growth and Crack Growth in Poly (Vinyl Chloride) under Monotonic and Fatigue Loading. Polymer, 17, 256-360. http://dx.doi.org/10.1016/0032-3861(76)90192-0

[20] Schirrer, R. and Goett, C.J. (1982) The Young's Modulus of the Craze in PMMA. Journal of Materials Science Letters, 1, 335-338.

[21] Trassaert, P. and Schirrer, R. (1983) The Disentanglement Time of the Craze Fibrils Polymethylmethacrylate. Journal of Materials Science, 18, 3004-3010. http://dx.doi.org/10.1007/BF00700782

[22] Sokkar, T.Z.N., El-Farahaty, K.A. and Azzam, A.A.S. (2014) On-Line Interferometric Study on the Mechanical Fracture Behaviour by Crazing Observed in Stretched Polypropylene Fibre. Fibres and Polymers, 15, 605-613.

[23] Schirrer, R., Josserand, L. and Davies, P. (1933) Fracture Surface Energy and Craze Fibril Stress in PMMA in Water. Journal De Physique IV, 3, 1553-1557.

[24] Pluta, M. (1971) A Double Refracting Interference Microscope with Continuously Variable Amount and Direction of Wavefront Shear. Optica Acta, 18, 661-675. http://dx.doi.org/10.1080/713818490

[25] Pluta, M. (1972) Interference Microscope of Polymer Fibres. Journal of Microscopy, 96, 309-332.

http://dx.doi.org/10.1111/j.1365-2818.1972.tb01061.x 
[26] Sokkar, T.Z.N., El-Tonsy, M., El-Morsy, M.A., El-khateep, S.M. and Raslan, M.I. (2011) Multi-Mode Opto-ThermoMechanical Stretching System for Determination of 3D Refractive Index along the Axis of the Stretched and/or Heated Fibre. Optics \& Laser Technology, 43, 1054-1060. http://dx.doi.org/10.1016/j.optlastec.2010.12.015

[27] Bower, D.I. (2002) An Introduction to Polymer Physics. Cambridge University Press, Cambridge. http://dx.doi.org/10.1017/CBO9780511801280

[28] Zbgniew, K.W. (1977) Formation of Synthetic Fibre. Gordon and Breuch Science Publishers, New York.

[29] Mcandrew, A. (2004) An Introduction to Digital Image Processing with Matlab for SCM25511 Image Processing. Victoria University of Technology.

[30] Williams, J.G. and Marshall, G.P. (1975) Environmental Crack and Craze Growth Phenomena in Polymers. Proceedings of the Royal Society, 42, 55-77. http://dx.doi.org/10.1098/rspa.1975.0012

[31] Hamza, A.A., Sokkar, T.Z.N. and Ramadan, W.A. (1992) On the Microinterfertric Determination of Refractive Indices and Birefringence of the Fibres. Pure and Applied Optics, 167, 161-177.

[32] Barakat, N. and Hamza, A.A. (1990) Interferometry of Fibrous Materials. Adam Hilger, Bristol. 
Scientific Research Publishing (SCIRP) is one of the largest Open Access journal publishers. It is currently publishing more than 200 open access, online, peer-reviewed journals covering a wide range of academic disciplines. SCIRP serves the worldwide academic communities and contributes to the progress and application of science with its publication.

Other selected journals from SCIRP are listed as below. Submit your manuscript to us via either submit@scirp.org or Online Submission Portal.
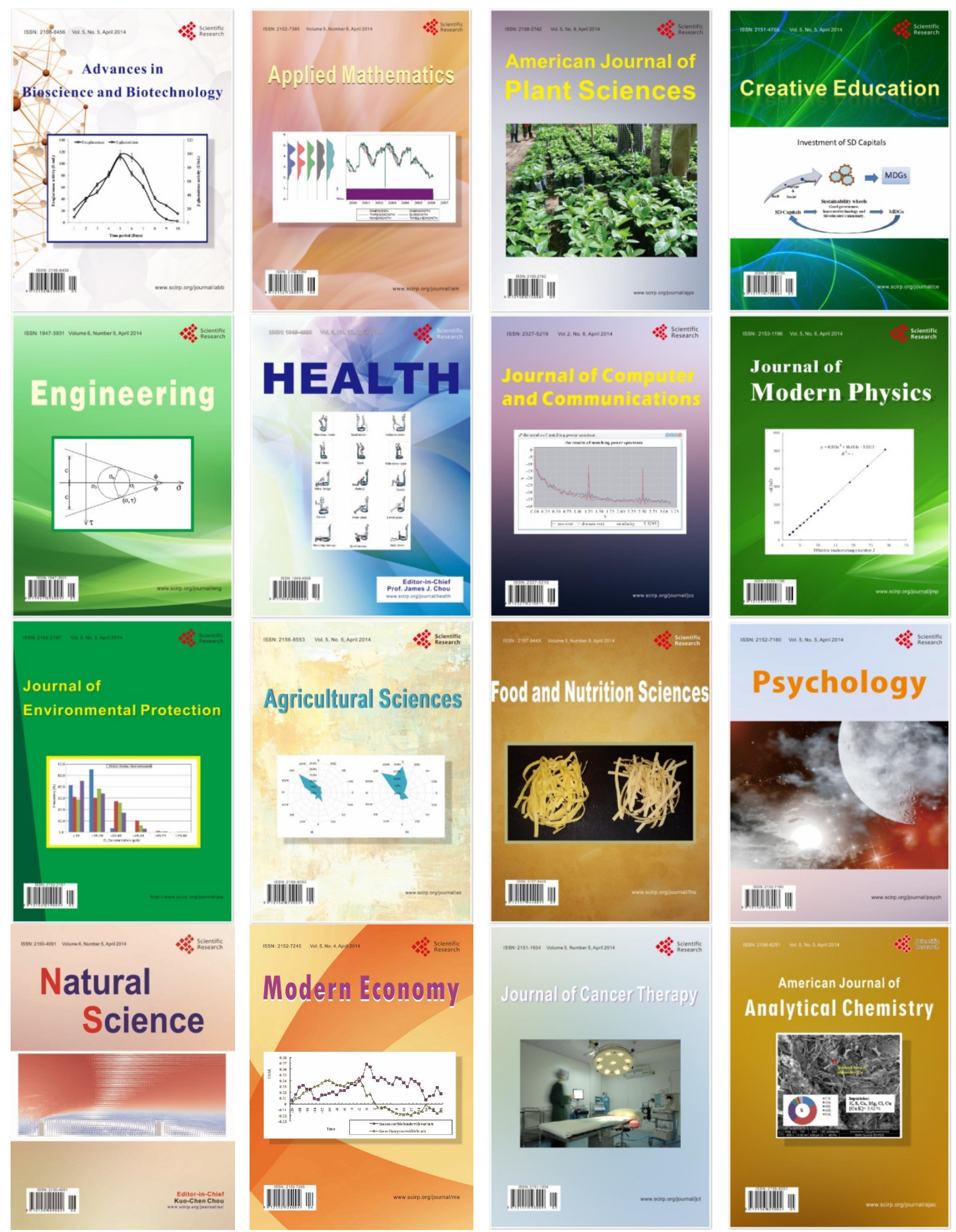